\title{
Somatization, Secondary Gain, and Chronic Pain: Is There a Relationship?
}

\author{
David A. Fishbain, M D
}

This article reviews the concept of somatization and its importance to chronic pain patients. In addition, this article addresses the hypothesis that some chronic pain patients may be using somatization for secondary gain. Evidence for this hypothesis is reviewed, and I conclude that there is very little scientific evidence to support this hypothesis now.

\section{Address}

Departments of Psychiatry, N eurological Surgery, and A nesthesiology, University of Miami School of Medicine, Comprehensive Pain and Rehabilitation Center at South Shore Hospital, 600 Alton Road, Miami Beach, FL 33139, USA.

Current Review of Pain 1998, 6:101-108

Current Science Inc. ISSN 1069-5850

Copyright $(\subset) 1998$ by Current Science Inc.

\section{$\mathrm{T}$} The term somatization has become extremely common in the medical literature, yet there is little agreement about its definition [1]. The most recent definition by Lipowski [2] defines somatization as "a tendency to experience and communicate somatic distress and symptoms that are unaccounted for by pathologic findings, to attribute them to physical illness, and to seek medical help for them. It is usual ly assumed that this tendency becomes manifested in response to psychosocial stress brought about by life events and situations personally stressful to the individual." Somatization does not represent a specific psychiatric or medical diagnosis and does not necessarily imply that a psychiatric disorder must be present [1]. Because somatization is not a specific diagnosis, it does not have operational criteria by which the diagnosis can be reached. This has been a detriment to the study of somatization per se and has led to authors using their own definitions and criteria. For example, Bridges and Goldberg [3] have recommended the use of the following criteria: 1) patients must seek help for somatic symptoms and not for psychologic manifestations of psychiatric disorder, 2) patients must attribute their symptoms to medical illness, and 3) patients must report symptoms that justify psychiatric diagnoses. Note that these criteria do not correlate with all the elements of Lipowski's definition for somatization. Lipowski [4] has in turn developed a different set of criteria for what is termed persistent somatization (Table 1).
Problems with definition and criteria for somatization will be discussed later in greater detail.

Somatization is very common. About $60 \%$ to $80 \%$ of physically heal thy people experience somatic symptoms in any given week [5]. Wallen et al. [6] reported that of 260,000 patients in 325 hospitals, $5.2 \%$ were placed in the diagnostic category of "symptoms and ill-defined conditions." However, somatization does not imply that the patient does not have a concurrent physical illness. Somatization can be, and most frequently is, comorbidly associated with physical diseases $[3,7]$. In addition, patients who are identified as somatizers often suffer from chronic illness and die early [8].

Major depression is frequently reported to be associated with somatization $[9,10]$. However, recent studies indicate that this observation may be overly simplistic. Chandler and Gerndt [11] have shown that a substantial number of elderly, depressed patients who allegedly had somatization disorder had in reality coexistent physical illness. In addition, when age and sex were controlled, patients suffering from depression were no more likely to have somatic complaints than patients who were diagnosed with other psychiatric illnesses. Therefore, it may be possible that the frequently reported association between depression and somatization reflects the preponderance of women and an increase in medical problems related to aging in the patient populations in which somatization is studied. This is the second problem with somatization research that will be discussed in greater detail.

Based on the information on somatization previously discussed, Sullivan and Katon [1] conduded that: 1) somatization

\section{Table 1. Criteria for Persistent Somatization}

Complaints of physical symptoms in the absence of relevant physical findings

Persistent fear or belief that the symptoms indicate serious physical illness despite reassurance by the physician to the contrary

Repeated search for medical help for the preceived symptoms

Partial or total disability as judged by occupational and social impairment

Duration of the above behavior for at least 6 months 
is very common, 2) somatization frequently coexists with medical illness, 3) a spectrum of severity from acute to chronic exists for somatization, and 4) most somatization is transient and treatable Sullivan and Katon [1] described three types of somatization reactions: 1 ) related to acute situational stress, 2) related to an acutepsychiatric disorder or disorders, and 3) related to a chronic psychiatric disorder or disorders.

Sullivan and Katon's [1] scheme is presented in Table 2. The table divides somatization reactions into those reactions that are related to acute situational stress, reactions that are related to acute psychiatric disorders, and reactions that are related to chronic psychiatric disorders. In somatization related to acute psychiatric disorder, the somatization is actually part of the psychiatric disorder, eg, depression [9,10,12-19].

Ford [19] pointed out somatization similarities among the Diagnostic and Statistical Manual of M ental Disorders, fourth edition, (DSM-IV) [20] somatoform disorders (hypochondriases, conversion disorder, somatization disorder, pain disorder, undifferentiated somatoform disorder, somatoform disorder not otherwise specified, body dysmorphic disorder), factitious disorders, and malingering and has grouped these as somatizing disorders (Table 2). Each of these diagnoses will be discussed later in relationship to its prevalence within the chronic pain patient (CPP) population according to the available research.

Finally, Table 2 lists some characteristics such as "pre occupation with health and symptoms," which appear to differ between the three types of somatization reactions.

\section{Somatization and the Chronic Pain Patient}

In their review, Sullivan and Katon [1] claimed that patients with chronic nonmalignant pain tend to have multiple nonpain physical complaints. However, they never reviewed the literature on pain for a basis to this

\section{Table 2. Somatization Reactions: Characteristics and Associated Syndromes}

\begin{tabular}{|c|c|c|}
\hline \multirow[b]{2}{*}{ Associated features } & \multicolumn{2}{|c|}{ Secondary somatization [12] } \\
\hline & $\begin{array}{l}\text { Somatization related to } \\
\text { acute situational stressor }\end{array}$ & $\begin{array}{l}\text { Somatization related to } \\
\text { acute psychiatric disorder }\end{array}$ \\
\hline Stressful life events & $\begin{array}{l}\text { Events cause symptoms that } \\
\text { cause patients to seek } \\
\text { treatment }\end{array}$ & $\begin{array}{l}\text { Symptoms are actually part } \\
\text { of the acute psychiatric } \\
\text { disorder, eg, insomnia }\end{array}$ \\
\hline $\begin{array}{l}\text { Associated psychiatric } \\
\text { diagnoses }\end{array}$ & Adjustment disorder [1] & $\begin{array}{l}\text { Major depression } \\
{[9,10,13-15]} \\
\text { Panic disorder }[16]\end{array}$ \\
\hline
\end{tabular}

Chronic problem (lasts

lifetime, some degree of disability) [1]

Preoccupation with health and symptoms

Fear or conviction of having a physical disease

Personality trait?

Likely to be persistent?

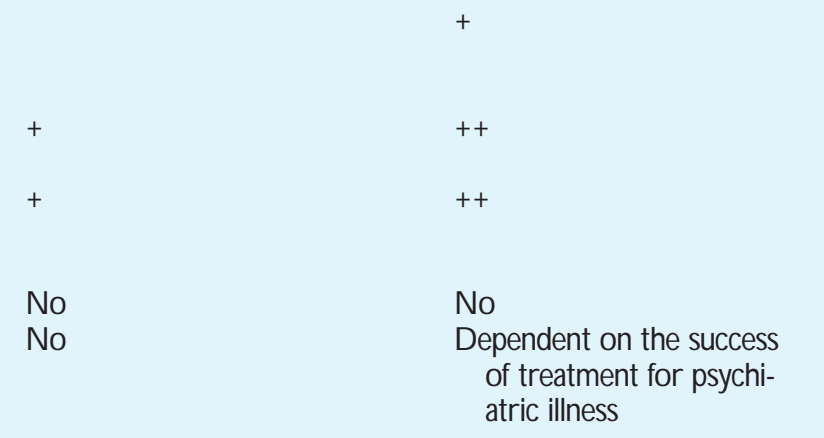

\section{Primary} somatization [12]

Somatization related to chronic psychiatric disorder

Symptoms related to their chronic psychiatric disorder

Hypochondriasis [17-19]

Pain disorder $[18,19]$

Somatization disorder $[18,19]$

Conversion disorder [18,19]

Body dysmorphic disorder $[18,19]$

Undifferentiated somatoform disorder [19]

Somatoform disorder not otherwise specified [19]

Factitious disorder $[18,19]$

Malingering (not a psychiatric disorder) $[18,19]$ $+++$

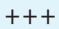

$+++$

Under investigation

Yes 
assertion but base their opinion on some family medicine studies. Here, the literature indicates that these symptoms account for $30 \%$ to $40 \%$ of ambulatory medical visits, with only a small percentage of these having an identifiable organic etiology [21].

A review of the studies on pain in the literature that have used somatization questionnaires indicates that several chronic pain studies do support this condusion. A high percentage of CPPs demonstrate elevated hypochondriasis scores [22] and somatization scores [23] as measured by the IIIness Behavior Questionnaire and the Modified Somatic Perceptions Questionnaire, respectively. In addition, when patients with various types of chronic pain are compared with appropriate controls on somatization measures, the CPPs are frequently demonstrated to have greater somatization scores. This finding has been demonstrated for CPPS with orofacial pain [24,25], migraines [26], noncardiac chest pain [27], dhronic low back pain [28], and fibromyalgia [29]. Finally, somatization scores appear to be predictors for treatment outcomein CPP with temporomandibular disorders [30] and low-back pain [31]. According to the somatization questionnaires, somatization may be a significant problem in CPPs, and patients with this problem may be at risk for poor treatment outcome.
There are al so several pain studies that have investigated somatization by looking at the frequency of various "somatizing disorders" in CPPS. Data for the somatizing disorders that have been investigated are presented in Table 3.

\section{Somatization Disorders}

Somatization disorder is the most important of the somatization reactions. This diagnosis is based on a history of many physical complaints beginning before age 30 years [20]. The diagnostic criteria for this disorder are presented in Table 4. Somatization disorder is the most extensively investigated, valid, and reliable of the chronic disorders associated with somatization. It is al so the most disabling [32]. However, its prevalence is low ( $1 \%$ of general population) [33], and it is often comorbidly associated with other psychiatric disorders [34]. Most patients with somatization disorder are comorbid for at least one other life time psychiatric disorder [19]. Here, the most common disorders (in decreasing frequency) are major depression, dysthymia, panic disorder, generalized anxiety disorder, substance abuse, and personality disorders [35,36]. As seen in Table 3, the frequency of somatization disorder in CPPs

\section{Table 3. Diagnostic Frequency of Somatizing Disorders in Chronic Pain Patients}

\begin{tabular}{|c|c|c|c|c|c|c|c|c|}
\hline & \multicolumn{8}{|c|}{ Study } \\
\hline & $\begin{array}{l}\text { Fishbain } \\
\text { et al. [48] }\end{array}$ & $\begin{array}{l}\text { Reich } \\
\text { et al. [49] }\end{array}$ & $\begin{array}{l}\text { Katon } \\
\text { et al. [50] }\end{array}$ & $\begin{array}{l}\text { Large } \\
\text { [51] }\end{array}$ & $\begin{array}{l}\text { Fishbain } \\
\text { et al. [46॰0] }\end{array}$ & $\begin{array}{l}\text { Fishbain } \\
\text { et al. [52] }\end{array}$ & King* & $\begin{array}{l}\text { Polatin } \\
\text { et al. [53] }\end{array}$ \\
\hline $\begin{array}{c}\text { Chronic pain } \\
\text { patients, } n\end{array}$ & 283 & 43 & 37 & 50 & N ot available & 2860 & 59 & 200 \\
\hline $\begin{array}{l}\text { Diagnostic mea- } \\
\text { sure }\end{array}$ & $\begin{array}{c}\text { DSM-III, 2-hr } \\
\text { semistruc- } \\
\text { tured } \\
\text { interview, } \\
\text { flowsheet }\end{array}$ & $\begin{array}{c}\text { DSM-III, } \\
\text { flow- } \\
\text { sheets }\end{array}$ & DSM-III, DIS & $\begin{array}{l}\text { DSM-III, } \\
\text { Maudsley } \\
\text { style }\end{array}$ & DSM-III & DSM-III & DSM-IV & $\begin{array}{l}\text { DSM-III-R, } \\
\text { SCID }\end{array}$ \\
\hline
\end{tabular}

\section{Diagnostic frequency, \%}

\begin{tabular}{|c|c|c|c|c|c|c|c|c|}
\hline $\begin{array}{l}\text { Somatoform } \\
\text { disorders }\end{array}$ & & & 16.2 & & & & & \\
\hline $\begin{array}{l}\text { Somatization } \\
\text { disorder }\end{array}$ & 3.9 & 5 & - & 8 & - & - & - & 1.0 \\
\hline $\begin{array}{l}\text { Conversion dis- } \\
\text { order }\end{array}$ & 37.8 & 2 & - & 8 & - & - & - & - \\
\hline $\begin{array}{l}\text { Psychogenic } \\
\text { pain/pain } \\
\text { disorder }\end{array}$ & 0.3 & 32 & - & - & - & - & 51.0 & 97.0 \\
\hline $\begin{array}{l}\text { Hypochondri- } \\
\text { asis }\end{array}$ & 0.7 & - & - & - & - & - & - & 1.0 \\
\hline $\begin{array}{l}\text { Factitious } \\
\text { disorders }\end{array}$ & - & 2.0 & - & - & - & 0.14 & - & - \\
\hline Malingering & - & - & & - & $0-22$ & - & - & - \\
\hline
\end{tabular}

*King SA, Paper presented at the Eighth W orld Congress on Pain,Vancouver, 1996.

DIS-N ational Institutes of Mental Health Interview Schedule; D SM-III-D iagnostic and Statistical Manual of Mental Disorders, edn 3;

D SM-III-R-D iagnostic and Statistical Manual of Mental Disorders, edn 3, revised; DSM-IV-Diagnostic and Statistical Manual of Mental Disorders, edn 4; SCID - Structured Clinical Interview for DSM. 
Table 4. Diagnostic Criteria for Hypochondriasis and Somatization Disorder*

\section{Hypochondriasis}

Fear of having, or belief that one has, serious disease based on misinterpretation of bodily sensations

Fear persists despite reassurance

Fear causes substantial distress or impairment

Duration of the disturbance is $>1$ month

Fear is not better accounted for by another mental disorder

\section{Somatization disorder}

History of many physical complaints beginning before age 30 , occurring over many years, and resulting in treatment seeking or impairment

Includes each of the following:

Four pain symptoms

Two gastrointestinal tract symptoms

0 ne sexual symptom

0 ne pseudoneurologic symptom

Includes either of the following:

Unexplained symptoms

Impairment exceeds that which would be warranted by physical findings

*Data from The American Psychiatric Association [20].

ranges from $3.9 \%$ to $16.2 \%$. This percentage range is higher than in the general population.

The next somatizing disorder is conversion disorder. In DSM-IV [20], conversion disorder has two criteria: 1) a loss or alteration of physical functioning suggesting a physical disorder, and 2) the presence of psychologic factors judged to be etiologically related to the symptom. That is, a temporal relationship should exist between a psychosocial stressor related to a psychologic conflict or need and initiation or exacerbation of the symptom. Psychologic issues are judged to be associated with initiating the symptom that is unconsciously produced and therefore not intentional or feigned [20]. Nonorganic physical findings that are often found in CPPs [37-39] can be considered to be equivalents of conversion symptoms. Fishbain et al. [39] haveshown that nondermatomal sensory abnormalities, as a conversion symptom, do not occur randomly in CPPs but rather in relationship to pain in the affected extremity. Such a result suggests that chronic pain coexists with conversion in CPPs, whatever the etiology for that pain. Finally, the psychologic criteria for this disorder do not protect the psychiatric consultant from a fal se-positive diagnostic error $[40,41]$, which can lead to disastrous medicolegal consequences. Thus, this diagnosis has questionable diagnostic validity, espedial ly for CPPs. As seen in Table 3, the range for conversion disorder in CPPs is from $2 \%$ to $37.8 \%$. The wide discrepancies in this range likely rel ate to the above criteria problems.

Pain disorder is the next somatizing disorder to be considered. This diagnosis [20] contains three basic criteria: 1 ) the pain must involve one or more anatomic sites and is the predominant focus of the clinical presentation (criteria A); 2) the pain must cause dinically significant distress and impairment in social, occupational, or other important areas of functioning (criteria B); and 3) psychologic factors must play an important role in the onset, severity, exacerbation, or maintenance of the pain (criteria $\mathrm{C}$ ). These are new criteria developed for the DSM-IV [20], and although an improvement over the old criteria, are likely to havelow reli- ability and validity and to be overindusive [42]. As seen in Table 3 the range for pain disorder in CPPs is from 3\% to $97 \%$. This widerange is al so a reflection of criteria problems.

The next somatizing disorder to be considered is hypochondriasis. This disorder is deemed as a preoccupation with having a serious illness [20]. Diagnostic criteria are presented in Table 4. Hypochondriasis is a chronic disorder [20]. Some authors report that it is rare [20], but others have reported a $4 \%$ to $6 \%$ prevalence in an internal medicine clinic [43]. It is often comorbidly associated with depression [17] or somatization disorder [44]. As seen in Table 3, the reported range for this diagnosis in CPPs is from $0.7 \%$ to $1 \%$. This range is lower than that reported for medical patients.

Thenext somatizing disorder, body dysmorphic disorder, is a preoccupation with an imaginary or slight physical defect in appearance such as hair or fadial features [20]. It is relatively uncommon and has significant psychiatric comorbidity, such as major depression [20]. There are no prevalence reports or case reports for body dysmorphic disorder in CPPs.

The next somatizing disorders to be considered are undifferentiated somatoform disorder and somatoform disorder not otherwise specified. Undifferentiated somatoform disorder is a diagnosis that is used for one or more unexplained physical symptoms [20]. Somatoform disorder not otherwise specified is a diagnosis reserved for somatic symptoms that have a prominent psychogenic component but do not fit the criteria of one of the other somatoform disorders, eg, psychogenic vomiting [20]. There are no reports for either of these disorders within CPPs.

Factitious disorder is the next somatizing disorder to be considered. The criteria for this disorder specify that physical or psychologic symptoms are consciously feigned in order to assume the sick role (secondary gain) for which there is unconscious motivation [20]. Factitious disorder is rare and is often comorbidly associated with personality disorders (borderline, antisocial) [45]. The reported range for this diagnosis in CPPs is from $0.14 \%$ to 
$2 \%$ (Table 3). This range is likely to be above that of the general medical population.

The next somatizing disorder is malingering. Malingering is not defined as a mental disorder, rather, it is an act and is therefore not an official psychiatric illness [20]. Malingering, is defined as the conscious and deliberate production, simulation, or exaggeration of a symptom for a conscious gain such as obtaining disability payments or avoiding military service [20]. There are few studies of malingering; therefore it is difficult to determine the prevalence of this condition. However, Fishbain et al. [46••] have recently reviewed the literature as it relates to pain. Fishbain et al. [46••] found that the range for reports on malingering in CPPs is between $0 \%$ and $22 \%$. This finding is in stark contrast to a report by the Institute of Medicine on pain and disability, which could not find any studies related to malingering and pain and concluded that malingering was rare in the chronic pain setting [47]. Fishbain et al. [46••] however, cautioned that the presented figures are likely to be incorrect due to the poor quality of the reviewed studies.

In all, the literature on pain and the prevalence of somatizing disorders in CPPs [48-53] indicates that, because of criteria difficulties, any figures are highly unreliable. However, it appears that somatizing disorders are present within this population.

\section{Secondary gain}

Barsky [54] has defined secondary gain as "acceptable or legitimateinterpersonal advantages that result when onehas the symptom of a physical disease" With respect to CPPs, the various types of identified secondary gains have been summarized in a recent review by Fishbain [55]. These secondary gains are presented in Table 5. Fishbain et al. [56•] al so reviewed the literature for studies related to the concept of secondary gain. Thirty-eight studies that addressed the concept of secondary gain were found. Of these, 18 dealt with chronic pain. Fishbain et al. [56•] concluded that pain and secondary gain research is weak and constrained by many methodologic flaws. However, receipt of disability benefits (a secondary gain) does dhange patient behavior, and spouses' solicitous responses to a CPPs' pain can serve as a secondary gain for that patient [56•].

Somatization and secondary gain may al so belinked in the same fashion as pain and secondary gain. For example, Ford [18] has pointed out that there are a number of factors that may facilitate the development of somatization. These factors are: social isolation; amplification (a tendency to experience somatic and visceral sensation as intense, noxious, and disturbing); alexithymia (inability to use words to describe emotional state); physiologic concomitants of psychiatric disorders such as insomnia; cultural attitudes; religious factors; stigmatization of psychiatric illness; economic issues; fashionable diagnoses, eg, reactive hypoglycemia; and the gains of illness, specifically secondary gain. Other authors have pointed out the adaptive advantages of somatization. Goldberg and Bridges [57] have claimed that somatization may be a way for the patient to avoid identifying himself or herself as mentally ill and that somatic symptoms provide excuses for other failings, ie, secondary gain. Mechanic [58] has claimed that the communication of somatic complaints may represent an attempt by the patient to attain certain personal objectives such as attention, release from social obligations and demands (or an excuse for failure to meet them), resolution of an inner or interpersonal conflict, support from others, or financial benefit. Similarly, other authors have claimed that because of these secondary gains, disability benefits serve as a disincentive to rehabilitation [59].

At issue then is whether these viewpoints and claims are anchored in substantive scientific studies, and whether there are substantive scientific studies that have addressed the possible relationship between secondary gain and somatization and the relationship among secondary gain, somatization, and chronic pain.

\section{Table 5. Secondary Gains to be Derived from Symptoms of Physical Disease}

Gratification of preexisting unresolved striving for dependency

Gratification of preexisting unresolved revengeful striving (eg, getting paid for not working in a setting where the employee felt unappreciated or was engaged in a risky job, revenge at insurance carriers or adjusters who gave the patient a hard time)

Attachment behavior or an attempt to elicit caretaking

0 versolicitousness and overprotectiveness by significant others

Family antagonism (anger) because of disability could increase patient resentment and determination to get his or her due and prove entitlement

Preferential or less hazardous work conditions or a means of avoiding work
Sympathy and concern from family and friends

A bility to withdraw from an unpleasant or unsatisfactory life role or activity

A bility to communicate and relate to others in a new, socially sanctioned manner

Financial rewards associated with disability

Access to drugs

Retaining the spouse in a marriage

Maintenance of family status

Maintenance of family love

A chieving or maintaining a dominant position in the family

Freedom from the socioemotional ("bread winner") role

Means of contraception 


\section{Somatization and Secondary Gain}

I was able to find only four studies $[60 \bullet, 61-63]$ that investigated the relationship between somatization and secondary gain. In the first study, Raskin et al. [63] judged secondary gain to have been present in $81 \%$ of 26 patients with hysterical conversion compared with only $28 \%$ of patients with an organic illness. In the second study, House and Andrews [62] found that discrimination between functional and organic dysphonia was enhanced when patient stressors were characterized on a dimension of "conflict over speaking out," defined as a situation in which a person wishes to protest or complain, but such forthrightness might lead to adverse consequences. In the third study of acute abdominal pain, Craig and Brown [61] determined that environmental events among the functionally ill were three times more likely to involve the breakup of a close relationship than were environmental events among the organically ill or healthy comparison groups. In the final study, Craig et al. [60•] categorized patients with somatic complaints into functional and organic disease based on evidence for organic disease. They also categorized life events previous to the illness for secondary gain potential based on a four-point rating scale (none, some, moderate, marked). It was found that in 38 weeks before symptom onset somatizers and psychologizers were more likely to have experienced at least one event that had secondary gain potential.

The previous studies indicate that, al though many writers have theorized about a link between somatization and secondary gain, there is very little evidence (four studies) for this relationship. In addition, there are problems with these studies in terms of how the presence of secondary gain was demonstrated. In Raskin et al.'s study [63], judgement was used to determine the presence of secondary gain. Similarly, in House and Andrews' study [62], judgement was used to make a decision about unconscious conflicts. In both of Craig et al.'s studies $[60 \bullet, 61]$ environmental events were characterized as having "potential for secondary gain" rather than determining whether the patient's behavior was motivated by secondary gain. Thus, there is very little evidence overall for a relationship between secondary gain and somatization.

\section{Somatization, Secondary Gain, and Pain}

To answer the question of whether there are substantive studies that indicate a clear relationship among somatization, secondary gain, and chronic pain, the literature was reviewed to isolate these studies. Only two studies [64,65] were found that could be construed to address the relationship among secondary gain, somatization, and chronic pain. In the first study [65], 250 CPPs were administered the SCL-90. All patients had elevated SCL-90 scores, but workers' compensation patients demonstrated the highest level of somatization. Because workers' compensation patients are often alleged to have secondary gains [56•], this study appears to support a relationship among secondary gain, somatization, and chronic pain. Similarly, the second study [64] also used workers' compensation CPPs, but here the Somatic Amplification Rating Scale (SARS) was used. The SARS is designed to quantify nonorganic physical findings that indicate either conversion problems or malingering. It was found that CPPs with high SARS scores were significantly more likely to be workers' compensation CPPs. These two studies then point to a potential relationship among somatization, chronic pain, and secondary gain.

\section{General Critique of the Somatization Literature}

The study of somatization has been approached in two major ways: 1) using operational diagnostic criteria as in the DSM system to arrive at a diagnosis for one of the somatizing disorders, and 2) using some kind of questionnaire that will measure somatization. Each of these approaches will be discussed and critiqued.

In reference to the operational criteria approach, researchers cannot agree on a definition for somatization and there are conflicting definitions. Therefore, a satisfactory operational diagnosis for somatization has not been developed, and the concept remains murky. Regarding the somatizing disorders, although operational criteria for these disorders exist, most of these diagnoses appear to have val idity problems. For the presence of secondary gain, as for somatization, there are no operational criteria [55]. Such a situation makes it difficult to link somatization with secondary gain in a valid, meaningful fashion.

The situation in determining the presence of malingering by questionnaire is subject to an even greater number of problems. These problems are as follows. When measuring somatization in CPPs by questionnaire, the first and major problem is to be sure that the measured somatization is not pain dependent, ie, it is independent of pain and pain levels. There is significant evidence that somatization scores using the SCL-90 are pain dependent [66-68]. This is important, because the tendency to somatize is conceptualized as a personality trait. Therefore, it should not be influenced by pain. The second major problem is that of the actual stability or test-retest reliability of such tests as the SCL-90. Fishbain [69] recently pointed out that the Minnesota Multiphasic Personality Inventory (MMPI), a psychologic test that contains a somatization scale, is not stable with pain treatment. That is, MMPI profiles change with treatment as pain improves. Because the MMPI is a personality test, scores are not supposed to change with pain treatment. A similar problem has been recently encountered with the SCL-90. Wallis et al. [70] demonstrated that SCL-90 profiles will change with successful pain treatment. The third major problem is that of depression. As previously described, many of the somatizing disorders are comorbidly associated with depression. 
In addition, depression is comorbidly associated with chronic pain and appears to be pain dependent [71•]. Yet none of the reviewed somatization studies attempted to control for depression. The fourth major problem is comorbidity of some of the major pain syndromes with identified physical disorders that would bias the results of somatization questionnaires. An example of this is fibromyal gia, which is comorbidly associated with irritable bowel syndrome, Raymond's phenomena, mitral valve prolapse, and hypermobility syndrome [72]. Each of these illnesses has a characteristic set of somatic complaints that can bias responses to a somatization questionnaire None of the reviewed somatization studies attempted to control for this problem.

In all, these four problems indicate that the issue of somatization is difficult to study. In addition, it is al so possible that because of these problems, much of what we currently know about somatization in CPPs could be incorrect.

\section{Condusions}

Somatization and some somatizing disorders are frequently encountered in the CPP population. Similarly, secondary gain is also allegedly encountered in CPPs and appears to change CPP behavior. At issue is whether somatization is used by some CPPs to satisfy a secondary gain agenda. The scientific evidence for this hypothesis is slim at best. Few studies have addressed this issue, although these studies appear to be consistent. As I pointed out, there are methodologic difficulties in determining who is and who is not somatizing and what normal somatization is in the context of chronic pain. Therefore, a decision on the validity of this hypothesis awaits further study.

\section{Acknowledgment}

This work was partially supported by National Institute on Disability and Rehabilitation Research grant number H133AOO032. The author wishes to thank Ms. Sandy Vassilatos for manuscript typing.

\section{References and Recommended Reading}

Papers of particular interest, published recently, have been highlighted as:

- Of special interest

-. Of outstanding interest

1. Sullivan $\mathbf{M}$, Katon $\mathbf{W}$ : The path between distress and somatic symptoms. Am Pain Soc J 1993, 2:141-149.

2. Lipowski Z): Somatization: the concept and its clinical application. Am J Psychiatry 1988, 145:1358-1366.

3. Bridges RN, Goldberg DP: Somatic presentation of DSM-III psychiatric disorders in primary care J Psychosom Res 1985, 29:563-569.

4. Lipowski Z): Somatization: a borderland between medicine and psychiatry. Can M ed Assoc J 1986, 135:609-614.
5. Kellner R, Sheffield BR: The one-week prevalence of symptoms in neurotic patients and normals. Am J Psychiatry 1973, 130:102-105.

6. Wallen J, Pincus HA, Goldman HH: Psychiatric consultations in short-term general hospitals. Arch Gen Psychiatry 1987, 44:163-168.

7. Ford CV: The somatizing disorders. Psychosomatics 1986, 27:327-337.

8. McFarland BH, Freeborn DK, Mullooly JP: Utilization patterns among long-term enrollees in a prepaid group practice health maintenance organization. M ed Care 1985, 23:1221-1233.

9. Katon W, Kleinman A, Rosen G: Depression and somatization: a review. Part I. Am J M ed 1982, 72:127-135.

10. Lipowski ZJ: Somatization and depression. Psychosomatics 1990, 31:13-21.

11. Chandler JD, Gerndt J: Somatization, depression and medical illness in psychiatric inpatients. Acta Psychiatr Scand 1988, 77:67-73.

12. Kroenke K: Somatization in primary care Am Pain Soc J 1993, 2:150-153.

13. Neitzert CS, Davis C, Kennedy SH: Personality factors related to the prevalence of somatic symptoms and medical complaints in a healthy student population. Br J M ed Psych 1997, 70:93-101.

14. Katon W: Depression: relationship to somatization and chronic medical illness. J Clin Psych 1984, 45:4-11.

15. Portegijs PJ, van der Horst FG, Proot IM, et al.: Somatization in frequent attendees of general practice Soc Psychiatry Psychiatr Epidemiol 1996, 31:29-37.

16. Noyes R, Reich J, Clancy J: Reduction in hypochondriasis with treatment of panic disorder. Br J Psychiatry 1986, 149:631-635.

17. Fischer-Homberger $\mathrm{E}$ : Hypochondriasis of the eighteenth century—neurosis of the present century. Bull H ist M ed 1972, 46:391-401.

18. Ford CV: Illness as a lifestyle - the role of somatization in medical practice. Spine 1992, 17:338-343.

19. Ford CV: Dimensions of somatization and hypochondriasis. N eurologic Clin 1995, 13:241-253.

20. American Psychiatric Association: D iagnostic and Statistical $M$ anual of M ental Disorders, edn 4. Washington, DC: American Press; 1994.

21. Kroenke K, Mangel sdorff A: Common symptoms in ambulatory care: incidence, evaluation, therapy, and outcome Am J M ed 1989, 86:262-266.

22. Pilowsky I, Spence ND: Patterns of illness behaviour in patients with intractable pain. J Psychosom Res 1975, 19:279-287.

23. Sikorski JM, Stampfer HG, Cole RM, et al.: Psychological aspects of chronic low back pain. Aust N Z J Surg 1996, 66:294-297.

24. Zach GA, Andreasen K: Evaluation of the psychological profiles of patients with signs and symptoms of temporomandibular disorders. J Prosthet D en 1991, 66:810-812.

25. McGregor NR, Butt HL, Zerbes M, et al.: Assessment of pain (distribution and onset), symptoms, SCL-90-R inventory responses, and the association with infectious events in patients with chronic orofacial pain. J O rofac Pain 1996, 10:339-350.

26. Merikangas KR, Stevens DE, Angst J: Headache and personal ity: results of a community sample of young adults. J Psych Res 1993, 27:187-196.

27. Serlie AW, Duivenvoorden HJ, Passchier J, et al.: Empirical psychological modeling of chest pain: a comparative study. J Psych Res 1996, 40:625-635.

28. Bacon NM, Bacon SF, Atkinson JH, et al.: Somatization symptoms in chronic low back pain patients. Psychosom M ed 1994, 56:118- 127. 
29. Ahles TA, Khan SA, Yunus MB, et al.: Psychiatric status of patients with primary fibromyal gia, patients with rheumatoid arthritis, and subjects without pain: a blind comparison of DSM-III diagnoses. Am J Psych 1991, 148:1721-1726.

30. Vassend O, Krogstad BS, Dahl BL: Negative affectivity, somatic complaints, and symptoms of temporomandibular disorders. J Psychosom Res 1995, 39:889-899.

31. Dionne CE, Koepsell TD, VonKorff M, et al.: Predicting longterm functional limitations among back pain patients in primary care settings. J Clin Epidemiol 1997, 50:31-43.

32. Smith GR, Monson RA, Ray DC: Patients with multiple unexplained symptoms. Arch Intern M ed 1986, 146:69-72.

33. Escobar JI: Cross-cultural aspects of the somatization trait. H osp Commun Psychiatr 1987, 38:174-180.

34. Liskow B, Othmer E, Penick EC: Is Briquet's syndrome a heterogenous disorder? Am J Psychiatr 1986, 143:626-629.

35. Brown FW, Golding JM, Smith GR Jr: Psychiatric comorbidity in primary care somatization disorder. Psych M ed 1990, 52(4):445-451.

36. Rost KM, Akins RN, Brown FW: The comorbidity of DSM-III-R personality disorders in somatization disorder. Gen H osp Psychiatr 1992, 14:322-326.

37. Rosomoff HL, Fishbain DA, Goldberg M, et al.: Physical findings in patients with chronic intractable benign pain of the neck and/or back. Pain 1989, 37:279-287.

38. Fishbain DA, Goldberg M, Steele Rosomoff R, et al.: Chronic pain patients and non-organic physical sign of nondermatomal sensory abnormalities (NDSA). Psychosomatics 1991, 32:294-303.

39. Fishbain DA, Goldberg M, Ferretti $\mathrm{T}$, et al.: The nondermatomal sensory abnormality (NDSA) and pain perception. Pain 1990, (suppl 5)S5-S332.

40. Fishbain DA, Goldberg M: The misdiagnosis of conversion disorder in a psychiatric emergency service Gen H osp Psychiatr 1991, 13:188-191.

41. Fishbain DA: The misdiagnosis of conversion disorder in a psychiatric emergency service Gen H osp Psychiatr 1992, 14:146-148.

42. Fishbain DA: DSM-IV: implications and issues for the pain clinician. Am Pain Soc Bull 1995, 6-18.

43. Barsky AJ, Wyashak G, Klerman GL: The prevalence of hypochondriasis in medical outpatients. Soc Psych Epidemiol 1990, 25:89-94.

44. Noyes R Jr, Holt CS, Happel RL, et al.: A family study of hypochondriasis. J N erv M ent Dis 1997, 185:223-232.

45. Nadelson T: False patients/real patients: a spectrum of disease presentation. Psychother Psychosomat 1985, 44:175-184.

46. •• Fishbain DA, Cutler R, Rosomoff HL, et al.: Chronic pain disability exaggeration/malingering: research. A review. Clin J Pain 1998, submitted for publication.

This review of the literature found that the range for reports on malingering in CPPs is between $0 \%$ and $22 \%$. This finding is in contrast to a report by the Institute of Medicine on pain and disability, which conduded that malingering is rare in the chronic pain setting.

47. Institute of Medicine: Pain and Disability, Clinical, Behavioral, and Public Policy Perspectives. Edited by Osterweis M, Kleinman A, Mechanic D. Washington, DC: National Academy Press; 1987.

48. Fishbain DA, Goldberg M, Meagher BR, et al.: Male and female chronic pain patients categorized by DSM-III psychiatric diagnostic criteria. Pain 1986, 26:181-197.

49. Reich J, Rosenblatt RM, Tupen J: DSM-III: a new nomenclature for classifying patients with chronic pain. Pain 1983, 16:201-206

50. Katon W, Egan K, Millder D: Chronic pain: lifetime psychiatric diagnoses and family history. Am J Psychiatry 1985, 142:1156-1160.

51. Large RG: DSM-III Diagnosis in chronic pain-confusion or clarity?J N erv M ent Dis 1986, 174:295-302.
52. Fishbain DA, Goldberg $M$, Steele Rosomoff $R$, et al.: More Munchausen with chronic pain. Clin J Pain 1991, 7:237-244.

53. Polatin PB, Kinney RK, Gatchel RJ, et al.: Psychiatric illness and chronic lowback pain. Spine 1993, 18:66-71.

54. Barsky AJ, Klerman GL: Overview: hypochondriasis bodily complaints and somatic styles. Am J Psychiatry 1983, 140:273-282.

55. Fishbain, DA: Secondary gain concept. Definition problems and its abuse in medical practice Am Pain Soc J 1994, (4):264-273.

56. Fishbain DA, Rosomoff HL, Cutler RB, et al.: Secondary gain concept: a review of the scientific evidence. Clin J Pain 1995, 11:6-21.

The authors review the concept of secondary gain and its application to the CPP.

57. Goldberg DP, Bridges K: Somatic presentations of psychiatric illness in primary care setting. J Psychosom Res 1988, 31:137-144.

58. Mechanic D: The concept of illness behavior: culture, situation and personal predisposition. Psychol M ed 1986, 16:1-7.

59. Better SR, Fine PR, Simson D, et al.: Disability benefits as disincentives to rehabilitation. H ealth Soc 1979, 57:412-427.

60. Craig TKJ, Drake H, Mills K, et al.: The South London somatization study: II. Influence of stressful life events, and secondary gain. Br J Psych 1994, 165:248-258.

The authors demonstrate a potential relationship between stresfful life events with secondary gain potential and the development of somatization.

61. Craig TK, Brown GW: Goal frustration and life events in the aetiology of painful gastrointestinal disorders. J Psychosomat Res 1985, 28:411-421.

62. House A, Andrews H: Life events and difficulties preceeding the onset of functional dysphonea. J Psychosomat Res 1988, 32:331-319.

63. Raskin M, Tal bott JA, Myerson AT: Diagnosis of conversion reactions: predictive value of psychiatric criteria. JAM A 1966, 197:530-534.

64. Korbon GA, DeGood DE, Schroeder ME, et al.: The development of a somatic amplification rating scale for low-back pain. Spine 1987, 12:787-791.

65. Cassisi JE, Sypert GW, Lagara L, et al.: Pain disability and psychosocial function in CLBP subgroups: myofascial versus herniated disc. N eurosurgery 1993, 33:379-385.

66. Larsson B, Melin L. Doberl A: Recurrent tension headache in adolescents treated with selfhel $p$ relaxation training and a muscle relaxant drug. H eadache 1990, 30:665-671.

67. Blanchard EB, Steffek BD, Jaccard J, et al.: Psychological changes accompanying non-pharmacological treatment of chronic headache: the effects of outcome H eadache 1991, 31:249-253.

68. Kluger NJ, Clifford JS, Cavanagh RJ, et al.: A case of a chemically dependent patient with a thalamic pain syndrome treated with amitriptyline J Addictive D is 1991, 10:97-102.

69. Fishbain DA: Some difficulties with the predictive validity of Minnesota multiphasic personality inventory. Pain Forum 1996, 5:81-82.

70. Wallis BJ, Lordes SM, Bogduk N: Resolution of psychological distress of whiplash patients following treatment by radiofrequency neurotomy: a randomized, double-blind, placebo-controlled trial. Pain 1997, 73:15-22

71. - Fishbain DA, Cutler R, Rosomoff HL, et al.: Chronic pain-associated depression: antecedent or consequence of chronic pain? A review. Clin J Pain 1997, 13:116-137.

This study suggests that depression is comorbidly associated with chronic pain and appears to be pain dependent.

72. Bennett, RM: Fibromyal gia and the facts: sense or nonsense Rheum D is Clin N orth Am 1993, 19:45-59. 